\title{
Secondary Neoplasm
}

National Cancer Institute

\section{Source}

National Cancer Institute. Secondary Neoplasm. NCI Thesaurus. Code C36255.

A neoplasm that arises from a pre-existing lower grade lesion, or as a result of a primary

lesion that has spread to secondary sites, or due to a complication of a cancer treatment. 